01,07

\title{
Влияние дополнительной интенсивной пластической деформации при повышенных температурах на микроструктуру и функциональные свойства ультрамелкозернистого сплава $\mathrm{Al}-0.4 \mathrm{Zr}$
}

\author{
(C) Т.С. Орлова ${ }^{1}$, Т.А. Латынина ${ }^{2}$, М.Ю. Мурашкин ${ }^{3,4}$, В.У. Казыханов ${ }^{4}$ \\ ${ }^{1}$ Физико-технический институт им. А.Ф. Иоффре РАН, \\ Санкт-Петербург, Россия \\ ${ }^{2}$ Санкт-Петербургский национальный исследовательский университет \\ информационных технологий, механики и оптики, \\ Санкт-Петербург, Россия \\ ${ }^{3}$ Санкт-Петербургский государственный университет, \\ Санкт-Петербург, Россия \\ ${ }^{4}$ Уфимский государственный авиационный технический университет, \\ Институт фозики перспективных материалов, \\ Уфра, Россия \\ E-mail: orlova.@@mail.ioffe.ru
}

Поступила в Редакцию 23 июля 2019 г.

В окончательной редакции 23 июля 2019 г.

Принята к публикации 24 июля 2019 г.

\begin{abstract}
Исследовалось влияние интенсивной пластической деформации кручения (ИПДК) при повышенных температурах 230 и $280^{\circ} \mathrm{C}$ на микроструктуру, механические свойства и электропроводность образцов ультрамелкозернистого (УМЗ) сплава $\mathrm{Al}-0.4 \mathrm{Zr}$. Исходная УМЗ-структура в материале исследования предварительно была сформирована в процессе ИПДК при комнатной температуре. Показано, что в результате дополнительной деформации УМЗ-сплава $\mathrm{Al}-0.4 \mathrm{Zr}$ при повышенных температурах происходит одновременное значительное увеличение прочности от 140 до $230-280 \mathrm{MPa}$ и электропроводности от $\sim 47.5 \%$ до 52-54\% IACS. Полученные результаты сравниваются с влиянием отжига при тех же температурах на микроструктуру и свойства УМЗ-сплава Al-0.4Zr. Установлено, что по сравнению с отжигом интенсивная пластическая деформация при аналогичных температурах приводит к более эффективному формированию наноразмерных выделений вторичной фазы $\mathrm{Al}_{3} \mathrm{Zr}$ и, следовательно, к большему уменьшению концентрации $\mathrm{Zr}$ в твердом растворе, что и обеспечивает значительное увеличение электропроводности. На основе полученных микроструктурных параметров проведены оценки вкладов различных механизмов упрочнения в общее упрочнение и механизмов рассеяния электронов в электросопротивление. Анализ теоретических оценок в сопоставлении с экспериментальными результатами указывает на то, что упрочнение в УМЗ-структуре $\mathrm{Al}-0.4 \mathrm{Zr}$ сплава, вызванное дополнительной ИПД при повышенных температурах, не может быть описано действием только традиционных для УМЗ-материалов механизмов упрочнения. Обсуждаются возможные причины полученного колоссального упрочнения.
\end{abstract}

Ключевые слова: ультрамелкозернистый алюминиевый сплав, интенсивная пластическая деформация, микроструктура, прочность, электропроводность, механизмы упрочнения.

DOI: 10.21883/FTT.2019.12.48582.558

\section{1. Введение}

Создание микроструктурного дизайна, обеспечивающего значительное повышение функциональных свойств металлов и сплавов, является одним из наиболее эффективных подходов современного физического материаловедения. Известно, что использование методов интенсивной пластической деформации (ИПД), приводящих к значительному измельчению зерна, позволяет в разы увеличить прочность ряда металлов и сплавов [1-6]. Однако ИПД приводит к повышению плотности дефектов кристаллической структуры (плотности дислокаций, протяженности границ зерен и других), что негативно сказывается на величине электропроводности. Поэтому получение проводниковых алюминиевых сплавов с одно- временно высокой прочностью и электропроводностью, а также повышенной термостабильностью механических свойств при температурах до $200^{\circ} \mathrm{C}$ является актуальной задачей. Для повышения термостабильности механических свойств важной легирующей добавкой является $\mathrm{Zr}$ с концентрацией $0.2-0.5 \mathrm{wt} \%$ [7,8].

Более того, недавно было показано, что для сплава $\mathrm{Al}-0.4 \mathrm{Zr}(\mathrm{wt} . \%)$ с ультрамелкозернистой (УМЗ) структурой, полученной методом интенсивной пластической деформации кручением (ИПДК), наблюдается значительное дополнительное упрочнение в результате низкотемпературного отжига при температурах $T_{\mathrm{AN}}=90-280^{\circ} \mathrm{C}$ с максимумом упрочнения (до $\sim 65 \%$ ) при $T_{\mathrm{AN}}=230^{\circ} \mathrm{C}[9]$. Примечательно, что как в исходном состоянии, полученном методом совмещенного литья и 
прокатки, так и в состоянии после ИПДК, $\mathrm{Zr}$ находился в основном в твердом растворе $[10,11]$. В области температур отжига $T_{\mathrm{AN}}=90-150^{\circ} \mathrm{C}$ эффект упрочнения для УМЗ-сплава $\mathrm{Al}-0.4 \mathrm{Zr}$ качественно и количественно был подобен таковому, наблюдаемому ранее в технически чистом Al [12]. При увеличении температуры отжига до $T_{\mathrm{AN}}=230^{\circ} \mathrm{C}$ наблюдалось дальнейшее упрочнение УМЗ-сплава, сопровождающееся понижением удельного электросопротивления, соответствующим повышению электропроводности от 47.4 до $48.7 \%$ IACS (значения электропроводности приведены в единицах IACS - International Annealed Copper Standard). Увеличение электропроводности происходило за счет уменьшения концентрации $\mathrm{Zr}$ в твердом растворе в результате формирования наноразмерных частиц вторичной фазы $\mathrm{Al}_{3} \mathrm{Zr}$. Однако, как было показано [9], колоссальный эффект упрочнения отжигом не может быть объяснен дисперсионным упрочнением.

Известно, что деформация алюминиевых сплавов при повышенных температурах может приводить к протеканию в них деформационного старения (ДС), которое, как правило, более эффективно способствует образованию наноразмерных частиц интерметаллидных фаз, чем отжиг при идентичных температурах. Например, для УМЗ-сплава Al-2Fe [13], структурированного интенсивной пластической деформацией при комнатной температуре (КТ), было показано, что применение дополнительной ИПД при повышенной температуре приводит к значительно более высокой электропроводности при одинаковом уровне прочности по сравнению с применением отжига при той же температуре. Для сплава системы $\mathrm{Al}-\mathrm{Mg}-\mathrm{Si}$ в УМ3-состоянии также была показана эффективность использования дополнительной ИПД при повышенных температурах для более глубокого распада твердого раствора и формирования наноразмерных частиц вторичных фаз в результате реализации ДС, что обеспечивало значительное повышение электропроводности при сохранении относительно высокого уровня прочности [1].

В настоящей работе было проведено исследование влияния ДС, реализуемого путем ИПДК при повышенных температурах, на микроструктуру, механические свойства и электропроводность сплава $\mathrm{Al}-0.4 \mathrm{Zr}$ в УМЗ-состоянии, сформированном предварительной обработкой ИПДК при КТ. Полученные результаты сравниваются с данными исследований о влиянии на микроструктуру и свойства УМЗ-сплава $\mathrm{Al}-0.4 \mathrm{Zr}$ отжигов, которые были получены нами ранее [9] и частично дополнены в настоящей работе.

\section{2. Материалы и экспериментальные методики}

Образцы исходного сплава $\mathrm{Al}-0.4 \mathrm{Zr}$ (wt.\%) с химическим составом $99.25 \mathrm{Al}, 0.393 \mathrm{Zr}, 0.023 \mathrm{Si}, 0.242 \mathrm{Fe}$, $0.018 \mathrm{Zn}, 0.026 \mathrm{~V}, 0.05$ - остальное (wt.\%) были получены методом совмещенного литья и прокатки компанией „РУСАЛ“ (Москва, Россия) [14,15]. В исходном состоянии (обозначенном далее „Initial“) атомы Zr преимущественно находятся в твердом растворе в алюминиевой матрице $[10,11]$. Заготовки в форме цилиндров с диаметром 9.5 и высотой $8 \mathrm{~mm}$ были нарезаны из исходного прутка и обработаны методом ИПДК при гидростатическом давлении $6 \mathrm{GPa}$ на 10 оборотов при КТ $[16,17]$. В результате такой обработки были получены образцы в форме дисков с диаметром 20 и толщиной $1.2 \mathrm{~mm}$. Истинная деформация на расстоянии $5 \mathrm{~mm}$ от центра диска составила $\gamma \approx 6.6$ [17]. В дальнейшем образцы, обработанные ИПДК при КТ, будем обозначать HPT_RT (high pressure torsion_room temperature). Часть образцов после ИПДК при КТ была обработана ИПДК под давлением $6 \mathrm{GPa}$ при повышенных температурах $T_{\mathrm{HPT}}=230$ и $280^{\circ} \mathrm{C}$ на $n=1,5,10$ и 20 оборотов. Далее образцы после двух этапов ИПДК при разных температурах будут обозначены как HPT_RT-HPT_T $T_{\mathrm{HPT}} n$. Выбор температур $T_{\mathrm{HPT}}=230$ и $280^{\circ} \mathrm{C}$ был обусловлен тем, что при отжиге образцов HPT_RT в течение $1 \mathrm{~h}$ максимальное упрочнение отжигом наблюдалось при температуре отжига $T_{\mathrm{AN}}=230^{\circ} \mathrm{C}$, а $T_{\mathrm{AN}}=280^{\circ} \mathrm{C}$ соответствовала концу температурного интервала, в котором наблюдалось упрочнение отжигом [9]. Для проведения ряда дополнительных исследований по влиянию отжига, несколько образцов после ИПДК при КТ были отожжены при температуре $230^{\circ} \mathrm{C}$ в течение 1 и $5 \mathrm{~h}$ аналогично тому, как это было сделано в [9]. Далее эти образцы обозначены как HPT_RT-AN_T $T_{\mathrm{AN}}$.

Микроструктура образцов изучалась методами рентгеноструктурного анализа (РСА), дифракции обратнорассеянных электронов (ДОРЭ), просвечивающей электронной микроскопии (ПЭМ). PCA проводился на дифрактометре Bruker D8 DISCOVER в стандартном режиме симметричного $\varphi-2 \varphi$-сканирования. На основе полученных рентгенограмм полнопрофильным моделированием методом Паули с использованием программного обеспечения TOPAS 5.0 определялись параметр решетки $a$, средний размер областей когерентного рассеяния $\left(D_{\mathrm{XRD}}\right)$, уровень микроискажений $\left(\left\langle\varepsilon^{2}\right\rangle^{1 / 2}\right)$. Плотность дислокаций $L_{d i s}$ рассчитывалась как [18]:

$$
L_{d i s}=\frac{2 \sqrt{3}\left\langle\varepsilon^{2}\right\rangle^{1 / 2}}{D_{\mathrm{XRD}} b},
$$

где $b=2.86 \AA-$ вектор Бюргерса.

Исследования методом ДОРЭ проводились на сканирующем электронном микроскопе Zeiss Merlin на области $\sim 1200 \mu \mathrm{m}^{2}$ с шагом сканирования $0.2 \mu \mathrm{m}$, для каждого состояния было проанализировано более 1000 зерен. По картам ДОРЭ были определены распределения зерен по размеру и границ зерен (БУГЗ) по углу разориентировки $(\theta)$. Средний размер зерна $\left(d_{a v}\right)$ определялся по методу реконструкции зерна [19]. Из полученных данных также были определены средний угол разориентировки ГЗ $\left(\theta_{a v}\right)$ и доля большеугловых границ зерен $(f \geq 15)$ с углом разориентировки $\theta \geq 15^{\circ}$.

Электронно-микроскопические исследования проводились на микроскопе JEOL JEM 2100. Тонкие фольги для 
исследований в ПЭМ были подготовлены механической полировкой с последующей двухструйной электрополировкой в режиме, представленном в [12].

Исследования механических свойств проводились путем измерения микротвердости и одноосного растяжения. Микротвердость по Виккерсу измерялась с помощью микротвердомера Shimadzu HMV-G с приложенной нагрузкой $1 \mathrm{~N}$ в течение $15 \mathrm{~s}$. Каждый образец был измерен не менее 15 раз.

Испытания на одноосное растяжение проводились на испытательной машине Shimadzu AG-XD Plus с постоянной скоростью деформации $5 \cdot 10^{-4} \mathrm{~s}^{-1}$. Для этого были вырезаны образцы в форме лопатки с шириной рабочей части $2 \mathrm{~mm}$ и длиной рабочей части $6 \mathrm{~mm}$. Схема вырезки и конфигурация образцов представлены в [9]. Деформацию образца регистрировали с помощью видеоэкстензометра TRViewX 55S. Для каждого состояния былы проведены испытания по меньшей мере трех образцов.

Электропроводность сплава $\omega_{\mathrm{RT}}$ при КТ измерялась с помощью вихретокового измерителя марки ВЭ-27 НЦ/4-5 с относительной погрешностью $\pm 2 \%$ по ГОСТ 27333-87. Кроме того, стандартным четырехточечным методом измерялось удельное сопротивление $\rho_{77}$ при $77 \mathrm{~K}$. Погрешность измерения электросопротивления составляла $<2 \%$. Температура образца контролировалась кремниевым диодом с точностью $\pm 0.03 \mathrm{~K}$. Более подробно измерение электрического сопротивления четырехточечным методом описано в [12].

\section{3. Экспериментальные результаты}

\section{1. Выбор параметров дополнительной ИПДК при повышенных температурах}

На рис. 1, $a$ представлены зависимости микротвердости $\left(H_{V}\right)$ сплава $\mathrm{Al}-0.4 \mathrm{Zr}$ в состоянии HPT_RT от количества оборотов дополнительной ИПДК при $T_{\mathrm{HPT}}=230^{\circ} \mathrm{C}$ (кривая 1) и $280^{\circ} \mathrm{C}$ (кривая 2). Значения микротвердости в исходном состоянии до ИПДК при КТ также представлены на рис. 1. Видно, что ИПДК при КТ значительно увеличивает микротвердость, что отмечалось ранее в [9]. Последующая ИПДК при $T_{\mathrm{HPT}}=230^{\circ} \mathrm{C}$ приводит к дальнейшему значительному увеличению $H_{V}$ до значения $820 \mathrm{MPa}$ уже после первого оборота кручения, однако в этом случае разброс значений микротвердости по рабочей зоне образца достаточно высок (рис. $1, a$ ), что скорее всего связано с тем, что после одного оборота еще не сформировалась достаточно однородная структура. При увеличении количества оборотов до $n=10$, среднее значение микротвердости остается на уровне $H_{V}=766 \mathrm{MPa}$, разброс значений по образцу становится незначительным. При увеличении $n$ до 20 оборотов среднее значение $H_{V}$ сохраняется. В случае дополнительной ИПДК при $T_{\mathrm{HPT}}=280^{\circ} \mathrm{C}$, величина $H_{V}$ сначала увеличивается и проходит через максимум при $n=1$, затем уменьшается почти линейно
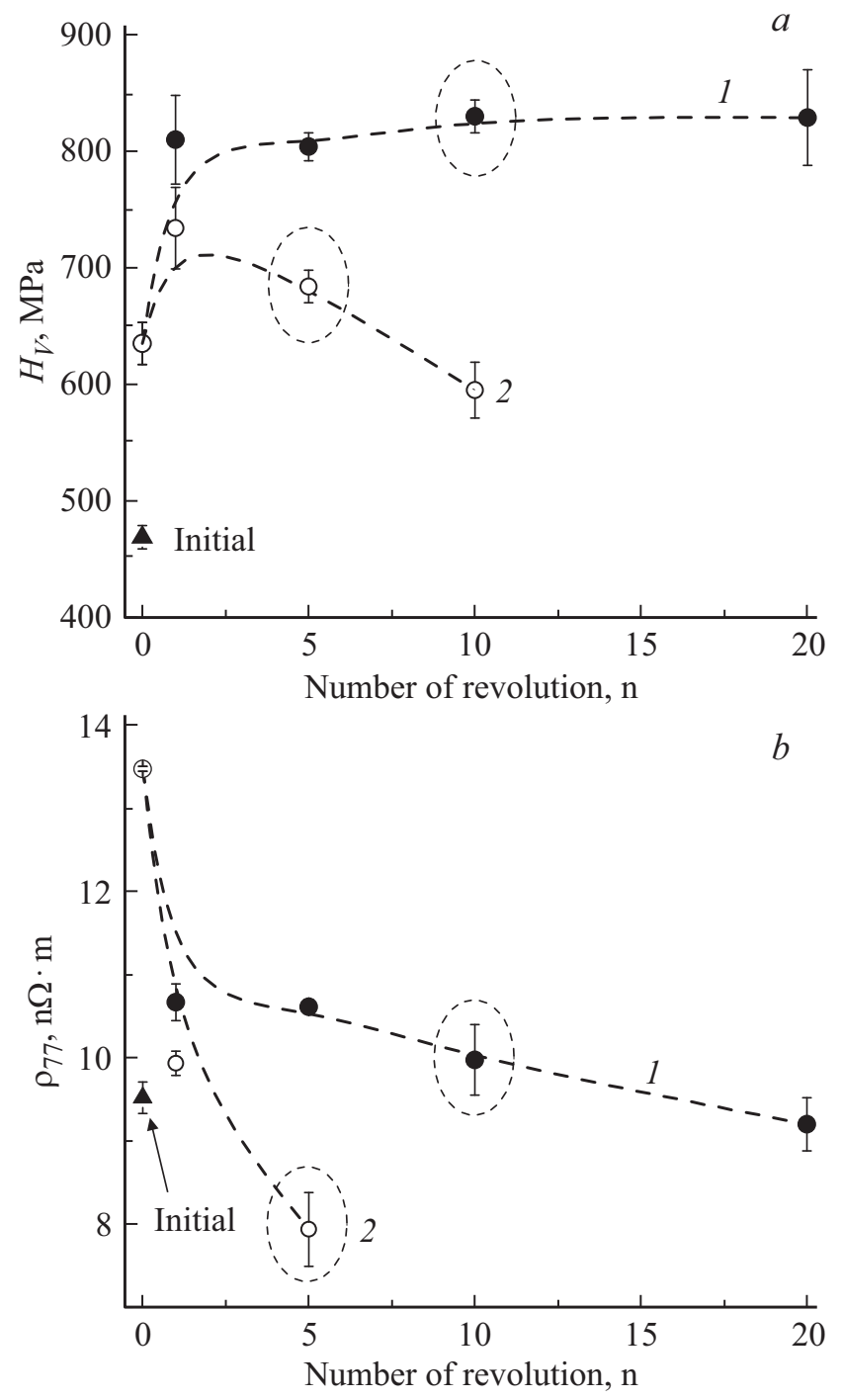

Рис. 1. Зависимости микротвердости $(a)$ и удельного электросопротивления при $77 \mathrm{~K}(b)$ для УМ3-сплава $\mathrm{Al}-0.4 \mathrm{Zr}$ (HPT_RT) от количества оборотов дополнительной ИПДК при повышенных температурах 230 (кривые 1 ) и $280^{\circ} \mathrm{C}$ (кривые 2). Значения $H_{V}$ и $\rho_{77}$ приведены также для исходного состояния (Initial).

с увеличением количества оборотов до $n=10$. Удельное сопротивление понижается при увеличении числа оборотов дополнительной ИПДК для обеих температур $T_{\mathrm{HPT}}=230$ и $280^{\circ} \mathrm{C}$ (рис. $1, b$ ). Для выяснения влияния числа оборотов на удельное сопротивление мы выбрали измерения сопротивления при $77 \mathrm{~K}$, так как при низких температурах влияние тепловых колебаний решетки, а также тепловых флуктуаций на электросопротивление понижено и, следовательно, относительное влияние микроструктурных элементов более выражено. Для дальнейших исследований были выбраны состояния с оптимальным сочетанием прочностных свойств (микротвердости) и электропроводности (удельного электросопротивления): HPT_RT-HPT_230_10 и HPT_RT-HPT_280_5, далее обозначенные, соответствен- 
Таблица 1. Данные ДОРЭ и РСА для исследуемых состояний сплава Al-Zr

\begin{tabular}{|c|c|c|c|c|c|c|c|c|}
\hline \multirow{2}{*}{ Обработка } & \multicolumn{3}{|c|}{ ДОРЭ } & \multicolumn{4}{|c|}{ PCA } & \multirow{2}{*}{ Ref. } \\
\hline & $d_{a v}, \mathrm{~nm}$ & $f_{\geq 15}, \%$ & $\theta_{\geq 15}$, grad & $\left\langle\varepsilon^{2}\right\rangle^{1 / 2}, \%$ & $D_{\mathrm{XRD}}, \mathrm{nm}$ & $a, \AA$ & $L_{d i s}, \mathrm{~m}^{-2}$ & \\
\hline Initial & $\begin{array}{l}\text { Length } 1790 \pm 20 \\
\text { Width } 1040 \pm 10\end{array}$ & 25 & 11.5 & $0.003 \pm 0.0001$ & $250 \pm 5$ & $4.0514 \pm 0.0001$ & $1.4 \cdot 10^{13}$ & {$[9]$} \\
\hline $\begin{array}{c}\text { HPT_RT } \\
\text { HPT_RT-HPT_230 } \\
\text { HPT_RT-HPT_280 }\end{array}$ & $\begin{array}{l}835 \pm 13 \\
920 \pm 15 \\
925 \pm 15\end{array}$ & $\begin{array}{l}82 \\
88 \\
89\end{array}$ & $\begin{array}{l}33.8 \\
36.2 \\
36.5\end{array}$ & $\begin{array}{l}0.063 \pm 0.0006 \\
0.036 \pm 0.0007 \\
0.022 \pm 0.0002\end{array}$ & $\begin{array}{l}210 \pm 10 \\
480 \pm 5 \\
560 \pm 25\end{array}$ & $\begin{array}{l}4.0515 \pm 0.0001 \\
4.0512 \pm 0.0001 \\
4.0514 \pm 0.0001\end{array}$ & \begin{tabular}{|l|}
$3.6 \cdot 10^{13}$ \\
$9.0 \cdot 10^{12}$ \\
$4.8 \cdot 10^{12}$
\end{tabular} & $\begin{array}{c}\text { Настоящая } \\
\text { работа }\end{array}$ \\
\hline HPT_RT-AN_230 & $880 \pm 15$ & 86 & 39.8 & $0.0300 \pm 0.0001$ & $505 \pm 10$ & $4.0516 \pm 0.0001$ & $7.2 \cdot 10^{12}$ & [9] \\
\hline
\end{tabular}
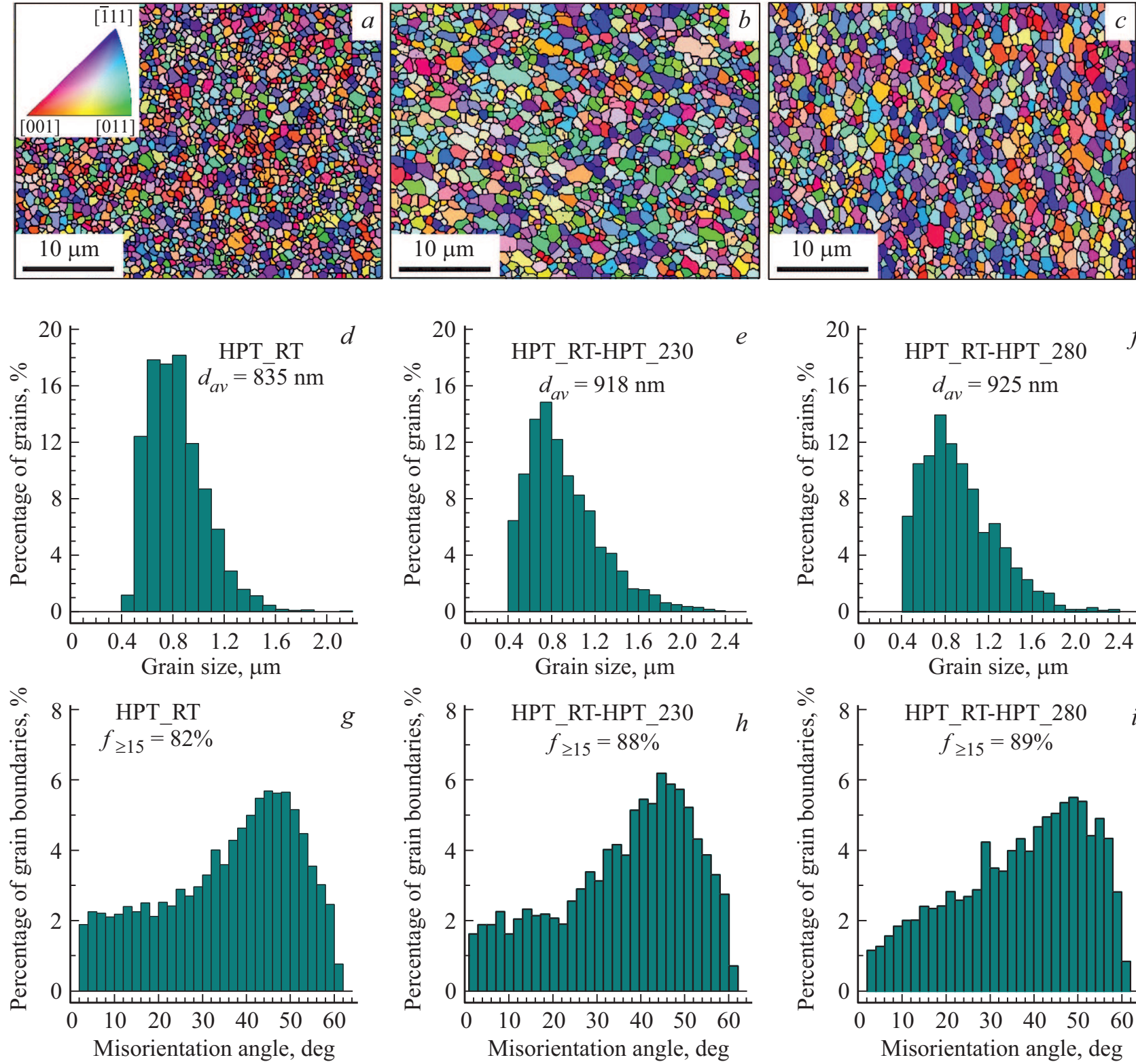
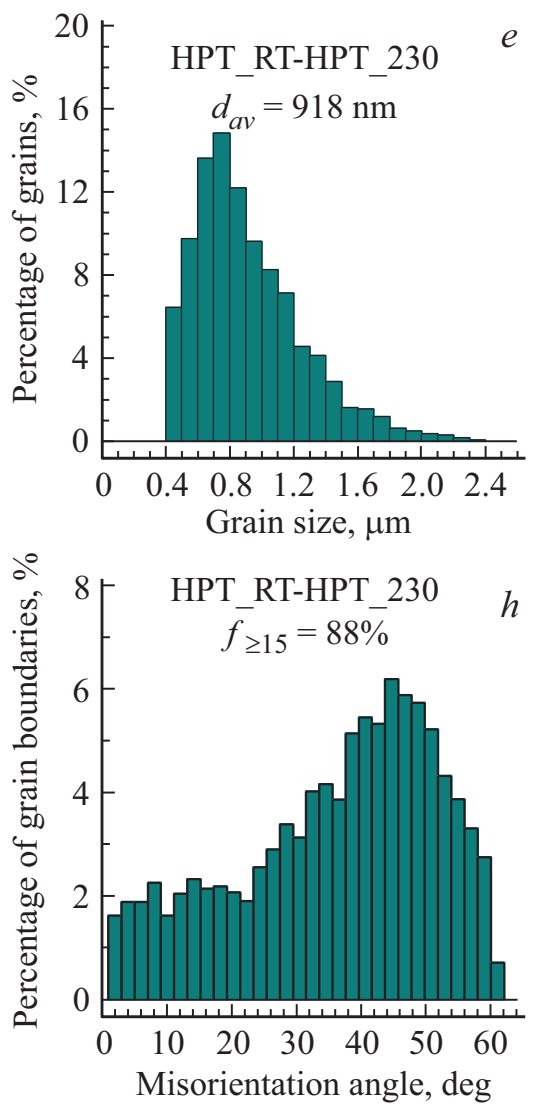
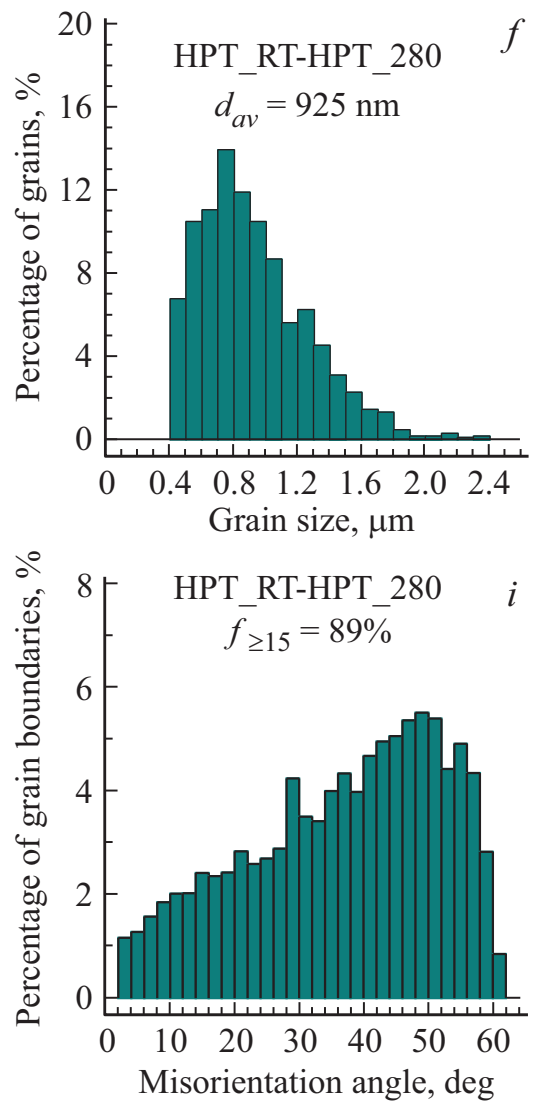

Рис. 2. Карты ДОРЭ $(a, b, c)$, распределение зерен по размеру $(d, e, f)$, распределение границ зерен по углам разориентировок $(g, h, i)$ для сплава Al-0.4Zr в состояниях HPT_RT $(a, d, g)$, HPT_RT-HPT_230 $(b, e, h)$ и HPT_RT-HPT_280 (c,f,i). 

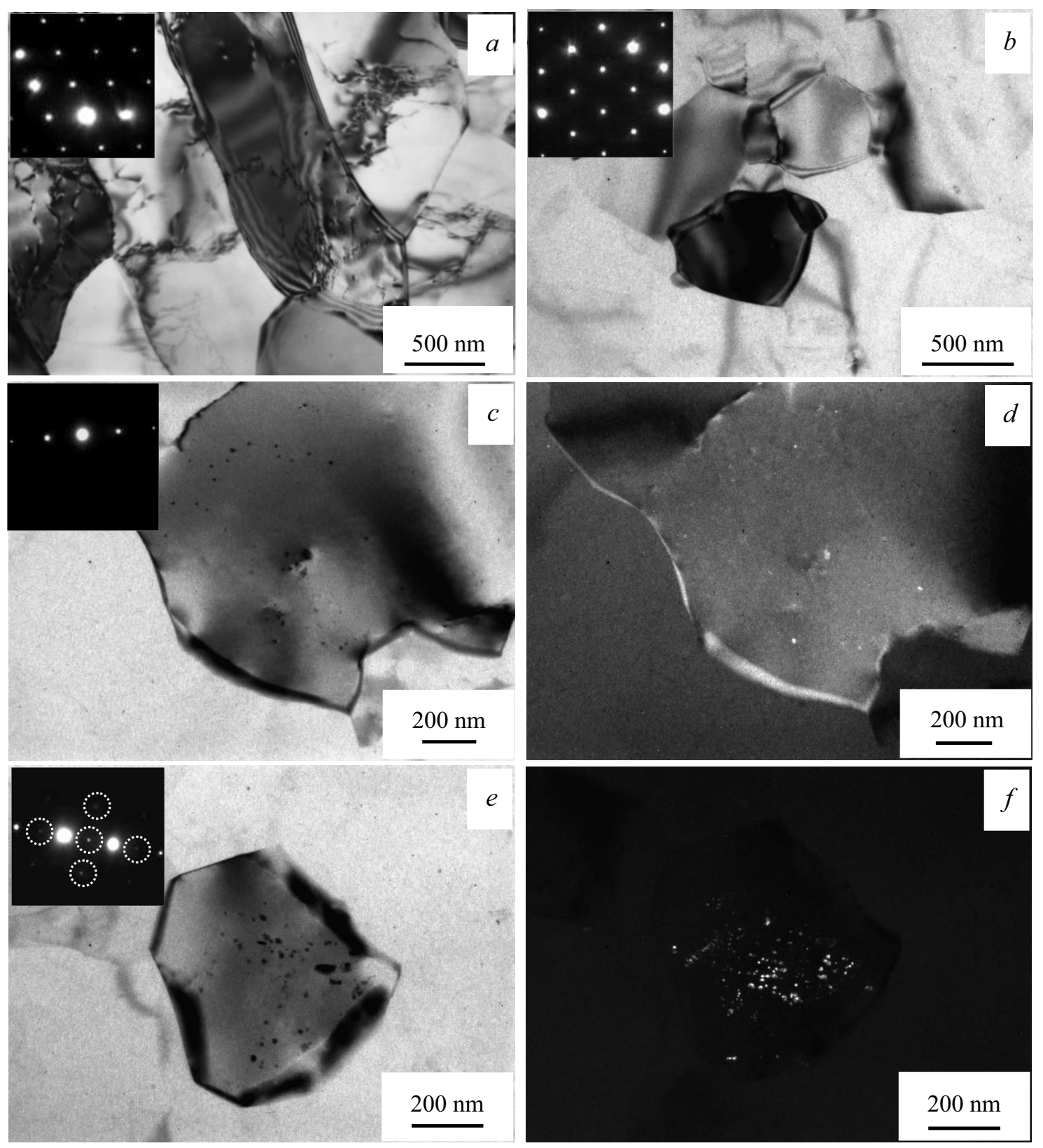

Рис. 3. ПЭМ-изображения с соответствующими дифракционными картинами, взятыми от отдельного зерна, для сплава $\mathrm{Al}-0.4 \mathrm{Zr}$ в состояниях: Initial $(a)$, HPT_RT $(b)$, HPT_RT-HPT_230 $(c, d)$ и HPT_RT-HPT_280 $(e, f) ; a, b, c, e)$ - светлопольные, d,f темнопольные изображения. $e-$ на дифракционной картине рефлексы от вторичной фазы $\mathrm{Al}_{3} \mathrm{Zr}$ выделены кружками.

но, как HPT_RT-HPT_230 и HPT_RT-HPT_280 (состояния, отмеченные кружками на рис. 1).

\section{2. Эволюция микроструктуры}

На рис. 2 представлены карты ДОРЭ и построенные на основе их анализа диаграммы распределения зерен по размерам и ГЗ по разориентировкам для сплава Al-0.4Zr в состояниях HPT_RT, HPT_RT-HPT_230 и HPT_RT-HPT_280. Результаты микроструктурных исследований представлены в табл. 1, дополнительно в ней приведены данные для сплава $\mathrm{Al}-0.4 \mathrm{Zr}$ в исходном состоянии (до обработки ИПДК), а также для сравнения в состояниях после ИПДК и отжига при $230^{\circ} \mathrm{C}$ (состояние HPT_RT-AN_230, данные работы [9]). Как уже отмечалось ранее $[9,20]$, исходное состояние сплава $\mathrm{Al}-0.4 \mathrm{Zr}$ характеризуется вытянутыми в направлении прокатки субзернами со средней длиной $\sim 1800$ и шириной $\sim 1000 \mathrm{~nm}$ (доля БУГЗ составляет 25\%) (табл. 1). Обработка ИПДК приводит к формированию однородной УМЗ структуры, образованной равноосными зернами, средний размер которых составляет $\sim 835 \mathrm{~nm}$, а доля БУГЗ достигает $82 \%$ (рис. $2, a, d, g$, табл. 1). После дополнительной ИПДК при $T_{\mathrm{HPT}}=230^{\circ} \mathrm{C}$ средний 
размер зерна составил $\sim 918 \mathrm{~nm}$, а доля БУГЗ $\sim 88 \%$ (рис. 2,b,e,h, табл. 1). Приблизительно такие же параметры микроструктуры $\left(d_{a v} \sim 925 \mathrm{~nm}\right.$ и $\left.f_{\geq 15} \sim 89 \%\right)$ были получены и после дополнительной ИПДК при $T_{\mathrm{HPT}}=280^{\circ} \mathrm{C}$ (рис. 2, c, f, $i$, табл. 1). Дополнительная ИПДК при температуре $230^{\circ} \mathrm{C}$ приводит лишь к незначительному увеличению среднего размера зерна и доли БУГЗ по сравнению с отжигом в течение $1 \mathrm{~h}$ при той же температуре (табл. 1). Следует отметить, что полученные распределения зерен по размерам и границ зерен по углам разориентации качественно подобны для образцов HPT_RT-HPT_230 (настоящая работа) и HPT_RT-AN_230[9].

Методом рентгеноструктурного анализа для сплава $\mathrm{Al}-0.4 \mathrm{Zr}$ были определены такие параметры микроструктуры, как параметр решетки $a$, средний размер областей когерентного рассеяния (ОКР) $D_{\mathrm{XRD}}$, уровень микроискажений $\left\langle\varepsilon^{2}\right\rangle^{1 / 2}$ и плотность дислокаций $L_{d i s}$, которые приведены в табл. 1. Вследствие предварительной обработки ИПДК при КТ, формирование УМЗ-структуры сопровождается заметным снижением среднего размера ОКР, увеличением уровня $\left\langle\varepsilon^{2}\right\rangle^{1 / 2}$, из чего, согласно формуле (1), последовало увеличение $L_{d i s}$ в $\sim 2$ раза. Дополнительная обработка ИПДК при температурах 230 и $280^{\circ} \mathrm{C}$ наряду с увеличением среднего размера зерна, приводит к значительному повышению размера ОКР и снижению значения $\left\langle\varepsilon^{2}\right\rangle^{1 / 2}$. При этом $L_{d i s}$ уменьшается в $\sim 4$ и $\sim 7.5$ раз соответственно (табл. 1). Отжиг УМЗ-сплава при температуре $230^{\circ} \mathrm{C}$ вызывает снижение $L_{d i s}$ приблизительно в 5 раз [9] (табл. 1). Таким образом, из сопоставления экспериментальных данных (табл. 1) видно, что дополнительная ИПДК при $230^{\circ} \mathrm{C}$ в УМЗ-материале менее эффективно понижает плотность дислокаций, чем отжиг. Отмеченное различие объясняется тем, что в процессе деформации при повышенной температуре дислокации не только аннигилируют, как происходит обычно во время отжига, но и образуются новые.

На рис. 3 представлены характерные изображения микроструктуры и дифракционные картины, взятые от отдельного зерна, полученные методом ПЭМ для образцов сплава $\mathrm{Al}-0.4 \mathrm{Zr}$ в состояниях Initial (рис. 3, a) HPT_RT (рис. 3,b), HPT_RT-HPT_230 (рис. 3,c,d), HPT_RT-HРT_280 (рис. 3,e,f). Аналогично [9], исследование методом ПЭМ не выявило присутствие наноразмерных выделений вторичной фазы, содержащей $\mathrm{Zr}$, в состояниях Initial и HPT_RT. Как было показано ранее, в сплаве $\mathrm{Al}-0.4 \mathrm{Zr}$ в исходном состоянии весь $\mathrm{Zr}$ находится в твердом растворе [10,11]. Аналогично отжигу при температуре $230^{\circ}$, ИПДК при $230^{\circ} \mathrm{C}$ приводит к образованию небольшого количества неравномерно распределенных наноразмерных частиц (рис. $3, c, d)$, что свидетельствует об уменьшении концентрации растворенных атомов $\mathrm{Zr}$ в твердом растворе Al. Количество выделившихся частиц увеличивается с повышением $T_{\mathrm{HPT}}$ до $280^{\circ} \mathrm{C}$ (рис. $3, e, f$ ). Об этом также свидетельствует появление дополнительных рефлексов от метастабильной фазы $\mathrm{Al}_{3} \mathrm{Zr}\left(\mathrm{Ll}_{2}\right)$ на дифракционной картине (рис. 3,e).
Количественная оценка среднего размера выделившихся частиц дала значения $18-19 \mathrm{~nm}$ для обоих состояний УМЗ-сплава HPT_RT-HPT_230 и HPT_RT-HPT_280.

\section{4. Механические свойства и электропроводность}

На рис. 4 представлено изменение микротвердости образцов HPT_RT в результате дополнительной ИПДК от температуры $T_{\mathrm{HPT}}$ (настоящая работа) и при отжиге в течение $1 \mathrm{~h}$ в зависимости от температуры отжига $T_{\mathrm{AN}}$ (данные работы [9]).

На рис. 5 приведены диаграммы растяжения образцов сплава $\mathrm{Al}-0.4 \mathrm{Zr}$ в различных состояниях: Initial, HPT_RT, HPT_RT-HPT_230, HPT_RT-HPT_280, а также для сравнения для образцов HPT_RT после отжига в течение $1 \mathrm{~h}$ при $230^{\circ} \mathrm{C}$ (данные работы [9]) и $280^{\circ} \mathrm{C}$ (данные настоящей работы) (соответственно состояния HPT_RT-AN_230, HPT_RT-AN_280). Определенные из экспериментальных диаграмм значения предела текучести $\sigma_{0.2}$, предела прочности $\sigma_{\mathrm{UTS}}$ и деформации до разрушения $\delta$ приведены в табл. 2. Видно, что ИПДК при повышенных температурах, также как и дополнительный отжиг, приводит к значительному увеличению прочности, при этом после дополнительной деформации полученные величины $H_{V}, \sigma_{0.2}, \sigma_{\mathrm{UTS}}$ даже несколько выше, чем после отжига при тех же температурах. Кроме того, для состояний HPT_RT-HPT_230, HPT_RT-HPT_280 на деформационных кривых наблюдается небольшой зуб текучести (рис. 5).

В табл. 2 приведены значения электропроводности $\sigma_{\mathrm{RT}}$ для всех исследованных состояний: Initial, HPT_RT,

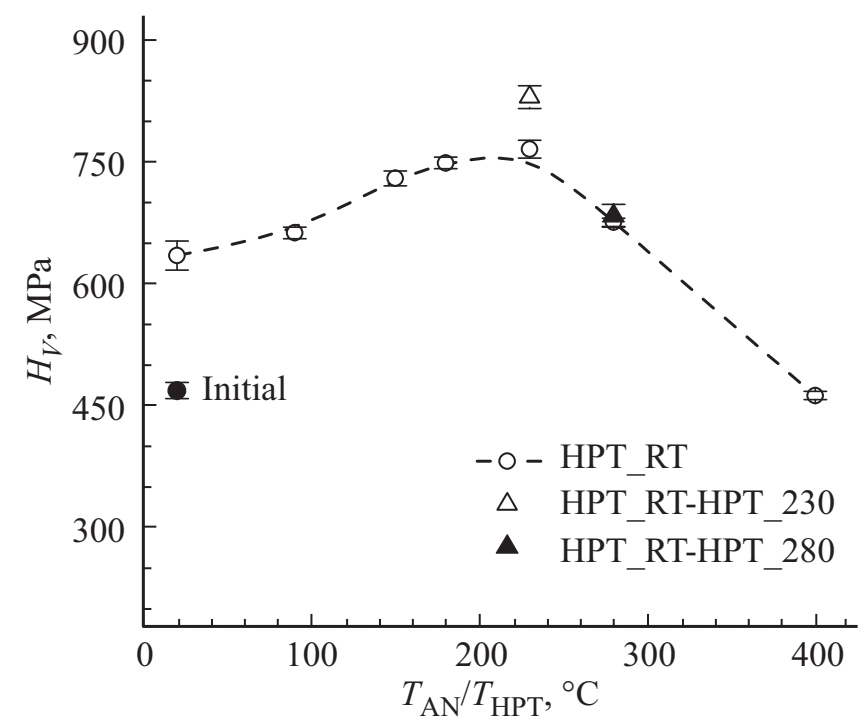

Рис. 4. Зависимость микротвердости УМЗ-сплава $\mathrm{Al}-0.4 \mathrm{Zr}$ (HPT_RT) от температуры дополнительной обработки ИПДК при повышенных температурах (HPT_RT-HPT_230 и HPT_RTHPT_230) (данные настоящей работы) и температуры дополнительного отжига (данные работы [9]). Значение $H_{V}$ приведено также для исходного состояния сплава (Initial). 
Таблица 2. Механические и электрические свойства сплава $\mathrm{Al}-0.4 \mathrm{Zr}$ в различных состояниях

\begin{tabular}{|c|c|c|c|c|c|c|c|}
\hline Обработка & $H_{V}, \mathrm{MPa}$ & $\sigma_{0.2}, \mathrm{MPa}$ & $\sigma_{\mathrm{UTS}}, \mathrm{MPa}$ & $\delta, \%$ & $\omega_{R T}, \% \mathrm{IACS}$ & $\rho_{77}, \mathrm{n} \Omega \cdot \mathrm{m}$ & Ref. \\
\hline Initial & $470 \pm 10$ & $120 \pm 2$ & $130 \pm 1$ & $25.9 \pm 0.2$ & $49.1 \pm 0.2$ & $9.5 \pm 0.2$ & {$[9]$} \\
\hline $\begin{array}{c}\text { HPT_RT } \\
\text { HPT_RT-HPT_230 } \\
\text { HPT_RT-HPT_280 }\end{array}$ & $\begin{array}{l}635 \pm 18 \\
830 \pm 14 \\
685 \pm 14\end{array}$ & $\begin{array}{l}140 \pm 2 \\
265 \pm 5 \\
230 \pm 2\end{array}$ & $\begin{array}{l}192 \pm 2 \\
276 \pm 7 \\
232 \pm 2\end{array}$ & $\begin{aligned} 23.2 & \pm 1 \\
7.7 & \pm 0.9 \\
15.7 & \pm 1\end{aligned}$ & $\begin{array}{l}47.4 \pm 0.1 \\
52.0 \pm 0.4 \\
54.2 \pm 0.7\end{array}$ & $\begin{aligned} 13.5 & \pm 0.1 \\
10.0 & \pm 0.4 \\
7.9 & \pm 0.5\end{aligned}$ & $\begin{array}{c}\text { Настоящая } \\
\text { работа }\end{array}$ \\
\hline HPT_RT-AN_230 & $765 \pm 11$ & $230 \pm 2$ & $250 \pm 4$ & $11.8 \pm 0.4$ & $48.7 \pm 0.2^{*}$ & $13.3 \pm 0.3$ & {$[9]$} \\
\hline $\begin{array}{l}\text { HPT_RT-AN_280 } \\
\text { HPT_RT-AN_230_5h }\end{array}$ & $\begin{array}{l}676 \pm 5^{* *} \\
750 \pm 10\end{array}$ & $\begin{array}{c}185 \pm 3 \\
-\end{array}$ & $\begin{array}{c}203 \pm 5 \\
-\end{array}$ & $\begin{array}{l}12.9 \pm 0.5 \\
\quad-\end{array}$ & $\begin{array}{l}50.3 \pm 0.4 \\
48.1 \pm 0.5\end{array}$ & $\begin{array}{l}12.0 \pm 0.6^{* *} \\
-\end{array}$ & $\begin{array}{l}\text { Настоящая } \\
\text { работа }\end{array}$ \\
\hline
\end{tabular}

Примечание. * данные настоящей работы, ** данные работы [9].

HPT_RT-HPT_230, HPT_RT-HPT_280, а также для сравнения состояний HPT_RT-AN_230, HPT_RT-AN_280, полученных в настоящей работе токовихревым методом. Сравнение изменения удельного электросопротивления $\rho_{77}$ при $77 \mathrm{~K}$ от температуры $T_{\mathrm{HPT}}$ или $T_{\mathrm{AN}}$ для УМЗ-сплава $\mathrm{Al}-0.4 \mathrm{Zr}$ показано на рис. 6. Видно, что дополнительная обработка НРТ при повышенных температурах 230 и $280^{\circ} \mathrm{C}$ приводит к значительному увеличению электропроводности при КТ и уменьшению $\rho_{77}$ соответственно на 3.5 и $5.6 \mathrm{n} \Omega \mathrm{m}$. В то время как в результате отжига при 230 и $280^{\circ} \mathrm{C}$ происходит

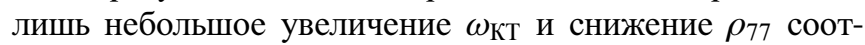
ветственно на 0.2 и $1.5 \mathrm{n} \Omega \mathrm{m}$. Примечательно, что величины как электропроводности, так и прочности (микротвердости) практически сохраняются при увеличении длительности отжига при $230^{\circ} \mathrm{C}$ до $5 \mathrm{~h}$ (табл. 2). Таким образом, как деформация, так и отжиг УМЗ-сплава при температуре $230^{\circ} \mathrm{C}$ приводят к значительному увеличению прочности $\left(\sigma_{0.2}\right.$ и $\left.\sigma_{\mathrm{UTS}}\right)$ с одновременным уве-

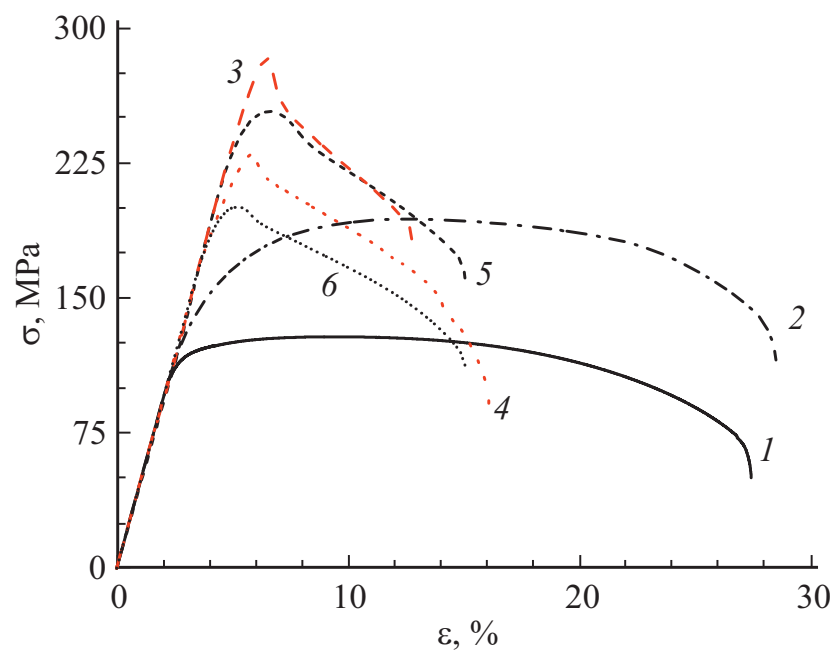

Pис. 5. Диаграммы растяжения для сплава $\mathrm{Al}-0.4 \mathrm{Zr}$ в исходном состоянии (1), после ИПДК при КТ (2) и после ИПДК при КТ и последующей ИПДК при повышенных температурах 230 (3) и $280^{\circ} \mathrm{C}$ (4) (данные настоящей работы), а также после обработки ИПДК при КТ и последующем отжиге в течение $1 \mathrm{~h}$ при $230^{\circ} \mathrm{C}(5)$ (данные работы [9]) и $280^{\circ} \mathrm{C}(6)$ (данные настоящей работы).

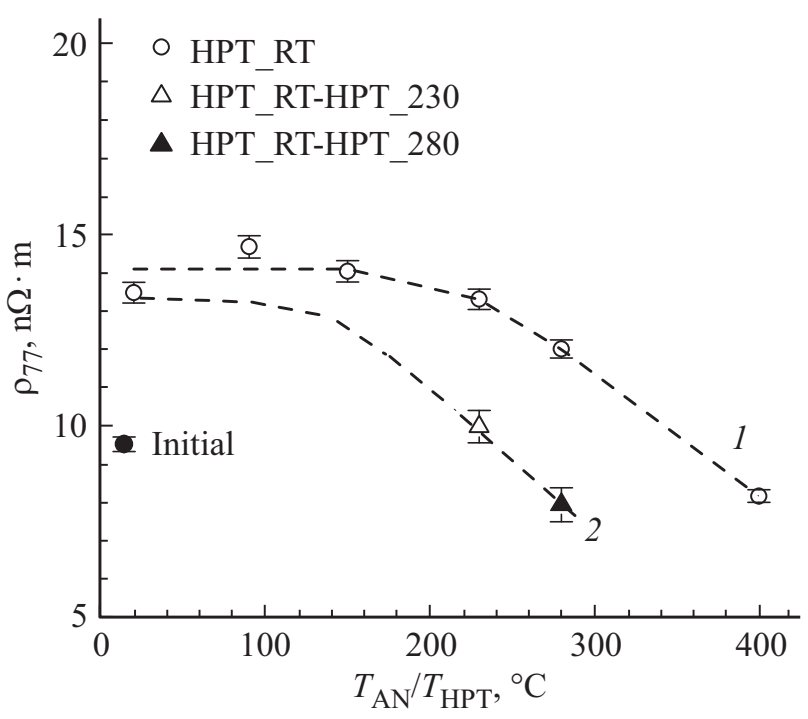

Рис. 6. Зависимости удельного сопротивления при $77 \mathrm{~K}$ для УМ3-сплава Al-0.4Zr (HPT_RT) от температуры отжига (кривая 1) (данные работы [9]) или температуры дополнительной обработки ИПДК (условная кривая 2) (данные настоящей работы).

личением электропроводности. Однако, дополнительная ИПДК при $230^{\circ} \mathrm{C}$ обеспечила гораздо более высокий уровень электропроводности (52\% IACS) по сравнению с отжигом $(\leq 49 \%$ IACS $)$ при той же температуре даже при увеличении его длительности до $5 \mathrm{~h}$, а также по сравнению с отжигом в течение $1 \mathrm{~h}$ при более высокой температуре $280^{\circ} \mathrm{C}$ ( 50\% IACS) (табл. 2).

\section{5. Обсуждение экспериментальных результатов}

После ИПДК при повышенной температуре, так же как и после отжига, максимальное упрочнение для УМЗ-сплава $\mathrm{Al}-0.4 \mathrm{Zr}$ было достигнуто при $T_{\mathrm{HPT}} / T_{\mathrm{AN}}=230^{\circ} \mathrm{C}$. Важно отметить, что упрочнение в обоих случаях сопровождалось одновременным заметным улучшением электропроводности. Поэтому проанализируем изменение прочности и электропроводности в 
сопоставлении с микроструктурными изменениями для состояния HPT_RT-HPT_230 в сравнении с таковыми для HPT_RT-AN_230.

Дополнительная ИПДК при $230^{\circ} \mathrm{C}$ привела к существенному снижению $\rho_{77}^{\exp }$ на $\sim 3.5 \mathrm{n} \Omega$ m. Согласно правилу Матиссена [21], в металлах и сплавах в области температур 77-300 K вклады различных механизмов рассеяния электронов в электросопротивление суммируются:

$$
\rho_{77}^{\text {th }}=\rho^{\text {pure }}+L_{d i s} \Delta \rho^{d i s}+S_{\mathrm{GB}} \Delta \rho^{\mathrm{GB}}+C_{\mathrm{Zr}}^{s o l} \Delta \rho_{\mathrm{Zr}}^{s o l}+\Delta \rho^{p t},
$$

где $\rho^{\text {pure }}=2.7 \mathrm{n} \Omega \mathrm{m}[22]-$ удельное сопротивление монокристаллического алюминия, $\Delta \rho^{d i s}=$ $=2.7 \cdot 10^{-25} \Omega \mathrm{m}^{3}[23], \Delta \rho^{\mathrm{GB}}=2.6 \cdot 10^{-16} \Omega \mathrm{m}^{2}[23]-$ вклады от удельной плотности дислокаций и границ зерен в $\mathrm{Al}$ соответственно, $\Delta \rho_{\mathrm{Zr}}^{\text {sol }}=15.8 \mathrm{n} \Omega \mathrm{m} / \mathrm{wt} . \%$ [24] вклад от удельной концентрации $Z r$ в твердом растворе, $L_{d i s}\left(\mathrm{~m}^{-2}\right)$ - плотность дислокаций, $S_{\mathrm{GB}}\left(\mathrm{m}^{-1}\right)-$ объемная плотность ГЗ, $C_{\mathrm{Zr}}^{\text {sol }}(\mathrm{wt} . \%)$ - концентрация растворенного в твердом растворе $\mathrm{Zr} ; \Delta \rho^{p t}-$ вклад от частиц вторичной фазы.

В слаболегированном сплаве $\mathrm{Al}-0.4 \mathrm{Zr}$ максимально возможный вклад $\Delta \rho^{p t}$ в электросопротивление пренебрежимо мал [9]. Проведенные оценки показали, что изменение плотности дислокаций и размера зерна после ИПДК при $230^{\circ} \mathrm{C}$ также дают пренебрежимо малые изменения вкладов от дислокаций $\left(\sim 7.3 \cdot 10^{-3} \mathrm{n} \Omega \mathrm{m}\right)$ и от границ зерен $(\sim 0.08 \mathrm{n} \Omega \mathrm{m})$, что значительно меньше наблюдаемого экспериментально изменения $\Delta \rho_{77} \sim 3.5 \mathrm{n} \Omega \mathrm{m}$. Как и в случае отжига [9], изменение $\rho_{77}$ после ИПДК при температуре $230^{\circ} \mathrm{C}$ связано главным образом с изменением концентрации $\mathrm{Zr}$ в твердом растворе в результате формирования частиц вторичной фазы. Изменение удельного сопротивления на $3.5 \mathrm{n} \Omega \mathrm{m}$ свидетельствует об уменьшении концентрации $\mathrm{Zr}$ в твердом растворе на $0.22 \mathrm{wt} . \%$, что соответствует формированию преципитатов $\mathrm{Al}_{3} \mathrm{Zr}$ общим объемом 0.27 vol.\%. Отметим, что ИПДК при повышенной температуре, когда в УМЗ материале активизируется процесс ДС, приводит к более эффективному (по сравнению с отжигом при той же температуре) уменьшению концентрации $\mathrm{Zr}$ в твердом растворе за счет формирования наноразмерных преципитатов вторичной фазы. По-видимому, это обусловлено тем, что в процессе ИПДК при повышенной температуре происходит более активное образование и аннигиляция вакансий из-за дополнительного деформационного воздействия, совмещенного с тепловым, которые могут ускорять диффузионные процессы, способствующие зарождению и формированию вторичных фаз. Кроме этого, в процессе ИПДК при повышенной температуре, в отличие от отжига, дислокации не только аннигилируют, но и генерируются как основные носители пластической деформации, что также может способствовать ускорению диффузии. ДС привело к большему увеличению электропроводности по сравнению с отжигом при той же температуре $230^{\circ} \mathrm{C}$, обусловленному более значительным уменьшением концентрации $\mathrm{Zr}$, растворенного в $\mathrm{Al}$ матрице: на 0.22 wt.\% при ДС и на 0.008 wt.\% при отжиге [9].

Обычно общее упрочнение металлов и сплавов является суммой вкладов различных механизмов в общее упрочнение [25]:

$$
\sigma_{0.2}^{t h}=\sigma_{0}+\sigma_{\mathrm{GB}}+\sigma_{d i s}+\sigma_{p t}+\sigma_{s o l},
$$

где $\sigma_{0}=10 \mathrm{MPa}$ - напряжение Пайерлса-Набарро кристаллической решетки $\mathrm{Al}[26], \sigma_{\mathrm{GB}}$ - упрочнение от границ зерен, $\sigma_{d i s}$ - дислокационное упрочнение, $\sigma_{p t}-$ примесное упрочнение частицами вторичной фазы и $\sigma_{\text {sol }}$ - твердорастворное упрочнение.

Зернограничное упрочнение определяется соотношением Холла-Петча [27]:

$$
\sigma_{\mathrm{GB}}=K d_{a v}^{-1 / 2}
$$

где: $\quad K=0.07 \mathrm{MPa} \cdot \mathrm{m}^{1 / 2}-$ коэффициент ХоллаПетча [28], $d_{a v}$ - средний размер зерна.

Вклад от дислокационного упрочнения оценивали по формуле Тэйлора [29]:

$$
\sigma_{d i s}=M \alpha \mathrm{GB} L_{d i s}^{1 / 2},
$$

где $M=3.06$ - фактор Тейлора [29], $\alpha=0.33$ параметр, учитывающий дислокационное взаимодействие [30], $G=26 \mathrm{GPa}$ - модуль сдвига, $b=2.86 \AA-$ вектор Бюргерса, $L_{d i s}$ - плотность дислокаций.

Согласно [31] твердорастворное упрочнение

$$
\sigma_{\text {sol }}=\sum_{i} k_{i} C_{i}^{2 / 3}
$$

где $C_{i}-$ концентрация $i$-го легирующего элемента, $k_{\mathrm{Zr}}=9 \mathrm{MPa} / \mathrm{wt} . \% \mathbf{0}^{2 / 3}$ - вычислено по данным [32]. Полученные оценки всех вкладов приведены в табл. 3 .

В крупнозернистых сплавах упрочнение частицами вторичной фазы может реализоваться различными путями: перерезанием частиц, посредством огибания их дислокационными петлями (механизм Орована) или комбинацией этих двух механизмов [33]. В [34] было показано, что в сплавах $\mathrm{Al}-\mathrm{Zr}$ с частицами больше, чем $4.0 \mathrm{~nm}$ в диаметре действует механизм Орована [33]:

$$
\Delta \sigma_{\mathrm{Or}}=\frac{0.4 M G_{\mathrm{Al}} b}{\pi \lambda \sqrt{1-V}} \ln \left(\frac{d_{a v} \pi}{4 b}\right),
$$

где $v=0.345$ - коэффициент Пуассона для Al [35], $\lambda$ - расстояние между примесными частицами, которое может быть вычислено из следующего уравнения [33]:

$$
\lambda=\frac{d_{a v}}{2}\left(\sqrt{\frac{2 \pi}{3 f_{V}}}-\frac{\pi}{2}\right),
$$

где $f_{V}$ - объемная доля преципитатов $\mathrm{Al}_{3} \mathrm{Zr}$.

Ранее было показано, что упрочнение по Оровану не реализуется в УМЗ-структуре предварительно состаренного сплава $\mathrm{Al}-0.4 \mathrm{Zr}$, несмотря на формирование в нем равномерно распределенных наноразмерных (диаметром $\sim 13 \mathrm{~nm}$ ) частиц фазы $\mathrm{Al}_{3} \mathrm{Zr}[20,36]$. 
Таблица 3. Результаты оценок вкладов возможных механизмов в общее упрочнение для сплава $\mathrm{Al}-0.4 \mathrm{Zr}$

\begin{tabular}{l|c|c|c|c|c|c|c|c}
\hline \multicolumn{1}{c|}{ Состояние } & $\sigma_{0}, \mathrm{MPa}$ & $\sigma_{\mathrm{GB}}, \mathrm{MPa}$ & $\sigma_{\text {sol }}^{*}, \mathrm{MPa}$ & $\sigma_{\text {dis }}, \mathrm{MPa}$ & $\sigma_{\mathrm{Or}}^{* *}, \mathrm{MPa}$ & $, \sigma_{0.2}^{\text {th }}, \mathrm{MPa}$ & $\sigma_{0.2}^{\text {exp }}, \mathrm{MPa}$ & Ref. \\
\hline Initial & 10 & 59 & 5 & 28 & 0 & 102 & 120 & Настоящая работа \\
HPT_RT & 10 & 77 & 5 & 45 & 0 & 137 & 140 & $\prime \prime$ \\
HPT_RT-HPT_230 & 10 & 73 & 5 & 23 & 60 & 171 & 265 & $\prime \prime$ \\
HPT_RT-AN_230 & 10 & 75 & 5 & 20 & 13 & 123 & 230 & {$[9]$}
\end{tabular}

Примечание. * максимально возможное упрочнение от твердого раствора при условии, что весь $\mathrm{Zr}$ находится в твердом растворе; ** максимально возможное упрочнение по Оровану.

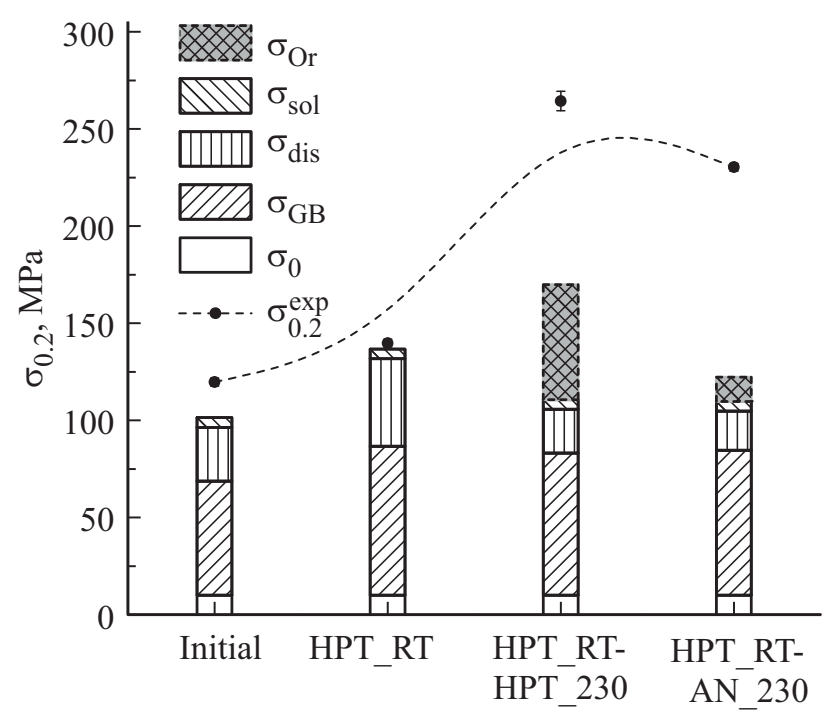

Рис. 7. Оценки вкладов возможных механизмов в упрочнение в сравнении с экспериментально полученными значениями условного предела текучести для сплава $\mathrm{Al}-0.4 \mathrm{Zr}$ в исходном состоянии (Initial) и в УМЗ-состояниях после ИПДК при КТ (HPT_RT), после ИПДК при КТ и ИПДК при $230^{\circ} \mathrm{C}$ (HPT_RTHPT_230) (данные настоящей работы) и после ИПДК при КТ и последующего отжига при $230^{\circ} \mathrm{C}$ (HPT_RT-AN_230) [9].

Следует заметить, что в HPT_RT-HРT_230 количество наноразмерных включений вторичной фазы невелико, а их распределение по образцу неоднородно (рис. $3, c, d$ ), поэтому упрочнение по Оровану, даже если оно и реализуется, не может быть значительным. Проведенные оценочные расчеты показали, что максимальный вклад в общее упрочнение от механизма Орована (если бы он реализовывался в идеальных условиях для данного УМЗ-материала: все частицы вторичной фазы размером $18 \mathrm{~nm}$ были бы гомогенно распределены в объеме образца) не будет превышать $60 \mathrm{MPa}$, тогда как полученная разница между $\sigma_{0.2}^{t h}$ и $\sigma_{0.2}^{\exp }$ (без учета упрочнения от частиц вторичных фаз) равна $154 \mathrm{MPa} \mathrm{для} \mathrm{состояния}$ HPT_RT-HPT_230 (табл. 3). В случае отжига при $230^{\circ} \mathrm{C}$, наблюдалось значительно меньшее количество частиц примерно с тем же средним размером и оценка вклада в упрочнение от них по механизму Орована составила менее $20 \mathrm{MPa}$ [9].

Экспериментальные и теоретические значения $\sigma_{0.2}$ находятся в хорошем соответствии для состояний до и по- сле ИПДК при КТ (табл. 3). Однако для УМЗ-состояний после ИПДК при $230^{\circ} \mathrm{C}$ экспериментальные значения $\sigma_{0.2}^{\text {th }}$ значительно (почти на $100 \mathrm{MPa}$ ) превышают полученные оценки $\sigma_{0.2}^{\text {th }}$ (табл. 3 , рис. 7) даже при учете максимально возможного вклада от упрочнения по механизму Орована. Подобное превышение значений $\sigma_{0.2}^{\exp }$ по сравнению с теоретическими оценками $\sigma_{0.2}^{\exp }$ характерно и для случая отжига при той же температуре (табл. 3, рис. 7) [9].

Таким образом, результаты проведенного анализа указывают на работу дополнительного механизма упрочнения в УМЗ-сплаве $\mathrm{Al}-0.4 \mathrm{Zr}$, вызванного микроструктурными изменениями вследствие ИПДК при повышенных температурах или отжига при той же температуре. Примечательно, что несмотря на существенно большее количество образовавшихся преципитатов и, как следствие, более значительное снижение концентрации циркония в твердом растворе в случае реализации ИПДК при повышенной температуре по сравнению с отжигом, уровни упрочнения $\left(\sigma_{0.2}\right.$ и $\left.\sigma_{\mathrm{UTS}}\right)$ УМЗ-сплава различаются незначительно. Отсутствие значимой разницы также косвенно указывает на то, что упрочнение за счет отжига или ИПДК при повышенной температуре не обусловлено реализаций механизма Орована. Наблюдаемое небольшое увеличение $\sigma_{0.2}^{\exp }$ в результате ИПДК при $230^{\circ} \mathrm{C}$ по сравнению со отжигом при $T_{\mathrm{AN}}=230^{\circ} \mathrm{C}$ связано главным образом с появлением зуба текучести в первом случае (рис. 5).

Аналогично случаю отжига [9], можно предположить, что дополнительное упрочнение УМЗ-сплава $\mathrm{Al}-0.4 \mathrm{Zr}$ в результате деформации при повышенной температуре, вероятнее всего, вызвано релаксацией БУГЗ [37-41], которая может сопровождаться образованием зернограничных примесных сегрегаций/нанокластеров/нанопреципитаций $[41,42]$. Поскольку известно, что ИПДК при повышенных температурах ускоряет диффузионные процессы в УМЗ-материалах, то ускоренная диффузия примесных атомов может приводить к закреплению ими дислокаций и вызвать появление зуба текучести на диаграммах деформирования в образцах HPT_RT-HPT_230 и HPT_RT-HPT_280 (рис. 5), подобно тому, как это наблюдалось для ряда алюминиевых сплавов (например, в [13,43]).

Примечательно, что для УМЗ $\mathrm{Al}-2 \mathrm{Fe}$ (wt.\%) сплава как отжиг при $200^{\circ} \mathrm{C}$, так и дополнительная деформация при $200^{\circ} \mathrm{C}$, приводили к значительному снижению $\sigma_{0.2}$, $\sigma_{\text {UTS }}($ почти в 2 раза), т. е. эффект упрочнения отжигом 
в этой системе не наблюдался, хотя УМЗ-структура была сформирована также ИПДК при подобных условиях [13]. Не наблюдался эффект упрочнения как после дополнительной ИПДК при повышенной температуpe [1], так и после отжигов [6] и в сплавах системы $\mathrm{Al}-\mathrm{Mg}-\mathrm{Si}$, в которых была предварительно сформирована УМЗ-структура методом ИПДК при КТ. Следует отметить, что в обеих этих системах дополнительная деформация при повышенных температурах приводила к формированию наноразмерных частиц вторичных фаз. Электропроводность в этих сплавах, как и в нашем материале исследования, увеличивалась за счет заметного снижения содержания легирующих элементов в твердом растворе, однако прочность УМЗ-сплавов систем $\mathrm{Al}-\mathrm{Fe}$ и $\mathrm{Al}-\mathrm{Mg}-\mathrm{Si}$ значительно снижалась. Уменьшение прочности в этих материалах при дополнительной деформации при повышенной температуре или при отжиге происходило главным образом за счет того, что размер ультрамелких зерен значительно увеличивался. В системе $\mathrm{Al}-0.4 \mathrm{Zr}$ размер зерна практически не изменяется как после дополнительной ИПДК при повышенных температурах, так и после отжига [9], что косвенно указывает на эффективность закрепления ГЗ и тройных стыков примесными сегрегациями и/или нанокластерами/нанопреципитациями.

\section{6. Заключение}

Проведены исследования влияния интенсивной пластической деформации кручения при температурах 230 и $280^{\circ} \mathrm{C}$ на микроструктуру, механические свойства и электропроводность УМЗ-сплава $\mathrm{Al}-0.4 \mathrm{Zr}$, УМЗ-структура которого была сформирована предварительной обработкой ИПДК при КТ. Показано, что после дополнительной ИПДК при температуре $230^{\circ} \mathrm{C}$, в УМЗ-сплаве удается одновременно повысить более чем в 1.5 раза прочностные характеристики $\left(\sigma_{0.2}\right.$ от 140 до $264 \mathrm{MPa}$ и $\sigma_{\text {UTS }}$ от 192 до $\left.276 \mathrm{MPa}\right)$ и электропроводность от 49 до $52 \%$ IACS.

Обнаруженная тенденция в изменении свойств (прочности и электропроводности) наблюдалась ранее в данном УМЗ-сплаве и после дополнительного отжига при той же температуре [9]. Однако деформация при повышенной температуре приводит к более заметному улучшению свойств УМЗ-сплава по сравнению с обычным отжигом. А именно, дополнительная ИПДК при температурах $T_{\mathrm{HPT}}=230-280^{\circ} \mathrm{C}$ обеспечила одновременное повышение прочности до уровня $\sigma_{\mathrm{UTS}}=230-280 \mathrm{MPa} \mathrm{и} \mathrm{электропроводности} \mathrm{до} \mathrm{значений}$ 52-54\% IACS, в то время как в результате отжига в течение $1 \mathrm{~h}$ при $T_{\mathrm{AN}}=230-280^{\circ} \mathrm{C}$ достигнута прочность $\sigma_{\mathrm{UTS}}=200-250 \mathrm{MPa}$ при уровне электропроводности 48.7-50.0\% IACS. Как и в случае отжига, максимальное упрочнение за счет дополнительной обработки ИПДК было достигнуто для $T_{\mathrm{HPT}}=230^{\circ} \mathrm{C}$.

Установлено, что деформационное старение, реализуемое в процессе дополнительной деформации методом
ИПДК при температуре $230^{\circ} \mathrm{C}$, в сравнении с отжигом при аналогичной или даже более высокой температуре $\left(280^{\circ} \mathrm{C}\right)$ приводит к образованию большей объемной доли наноразмерных частиц метастабильной фазы $\mathrm{Al}_{3} \mathrm{Zr}$, соответственно к более значительному уменьшению концентрации $\mathrm{Zr}$ в твердом растворе УМЗ-алюминия, что обеспечивает значительное увеличение электропроводности.

Показано, что после дополнительной ИПДК при повышенной температуре в УМЗ-сплаве наблюдается небольшое увеличение размера зерна, уменьшение плотности дислокаций и концентрации $\mathrm{Zr}$ в твердом растворе, что должно было бы приводить к разупрочнению, в то время как экспериментально обнаружен нестандартный характер изменения прочности - значительное упрочнение.

Проведенные оценки возможного упрочнения в результате формирования наноразмерных выделений вторичной фазы $\mathrm{Al}_{3} \mathrm{Zr}$, вызванного динамическим старением при ИПДК при $T_{\mathrm{HPT}}=230^{\circ} \mathrm{C}$, показали, что наблюдаемое упрочнение не может быть объяснено дисперсионным упрочнением от этих выделений. Возможными причинами упрочнения УМЗ-сплава $\mathrm{Al}-0.4 \mathrm{Zr}$ при дополнительной ИПДК при повышенной температуре, так же как и при отжиге, может быть релаксация неравновесных границ зерен и образование, наряду с внутризеренными частицами метастабильной фазы $\mathrm{Al}_{3} \mathrm{Zr}$, зернограничных сегрегаций и/или нанокластеров/нанопреципитаций.

\section{Конфликт интересов}

Авторы заявляют, что у них нет конфликта интересов.

\section{Список литературы}

[1] R.Z. Valiev, M.Yu. Murashkin, I. Sabirov. Scr. Mater. 76, 13 (2014).

[2] E.V. Bobruk, M.Yu. Murashkin, V.U. Kazykhanov, R.Z. Valiev. Rev. Adv. Mater. Sci. 31, 109 (2012).

[3] А.М. Мавлютов, И.А. Касаткин, М.Ю. Мурашкин, Р.3. Валиев, Т.С. Орлова. ФТТ 57, 10, 2051 (2015).

[4] R.Z. Valiev, A.P. Zhilyaev, T.G. Langdon. Bulk Nanostructured Materials: Fundamentals and Applications, John Wiley \& Sons. (2013).

[5] I. Sabirov, M.Y. Murashkin, R.Z. Valiev. Mater. Sci. Eng. A 560, 1 (2013).

[6] X. Sauvage, E.V. Bobruk, M.Y. Murashkin, Y. Nasedkina, N.A. Enikeev, R.Z. Valiev. Acta Mater. 98, 355 (2015).

[7] T. Knych, M. Piwowarska, P. Uliasz. Arch. Met. Mater. 56, 685 (2011).

[8] Д.И. Белый. Кабели и провода 332, 8 (2012).

[9] T.A. Latynina, A.M. Mavlyutov, M.Yu. Murashkin, R.Z. Valiev, T.S. Orlova. Phil. Mag. 99. 19, 2424 (2019). DOI: $10.1080 / 14786435.2019 .1631501$

[10] K.E. Knipling, D.C. Dunand, D.N. Seidman. Z. Metallk. 97, 246 (2006).

[11] N.A. Belov, A.N. Alabin, A.R. Teleuova. Met. Sci. Heat Treat. 53, 455 (2012).

[12] T.S. Orlova, A.M. Mavlyutov, A.S. Bondarenko, I.A. Kasatkin, M.Y. Murashkin, R.Z. Valiev. Phil. Mag. 96, 23, 2429 (2016). 
[13] A.E. Medvedev, M.Y. Murashkin, N.A. Enikeev, R.Z. Valiev, P.D. Hodgson, R. Lapovok. Adv. Eng. Mater. 20, 3, 1700867 (2018).

[14] P. Ilario. Machine for the continuous casting of metal rods, US 2659948 (1953).

[15] R.J. Schoerner. Method of fabricating aluminum alloy rod, US 3670401 (1972).

[16] R.Z. Valiev, R.K. Islamgaliev, I.V. Alexandrov. Prog. Mater. Sci. 45, 103 (2000).

[17] A.P. Zhilyaev, T.G. Langdon. Prog. Mater. Sci. 53, 893 (2008).

[18] G.K. Williamson, R.E. Smallman. Philos. Mag. 1, 34 (1956).

[19] F.J. Humphreys. J. Microsc. 195, 170 (1999).

[20] А.М. Мавлютов, Т.А. Латынина, М.Ю. Мурашкин, Р.З. Валиев, Т.С. Орлова. Материаловедение 3, 7 (2018).

[21] P.L. Rossiter. The Electrical Resistivity of Metals and Alloys. Cambridge University Press, Cambridge (2003).

[22] Properties and Selection: Nonferrous Alloys and SpecialPurpose Materials, ASM Handbook, ASM International (1990).

[23] A.S. Karolik, A.A. Luchvich. J. Phys.: Condens. Matter. 6, 873 (1994).

[24] F. Kutner, G. Lang. Aluminum. 52, 322 (1976).

[25] N. Kamikawa, X. Huang, N. Tsuji, N. Hansen. Acta Mater. 57, 4198 (2009).

[26] G.E. Totten, D.S. MacKenzie. Handbook of Aluminium, Marcel Dekker (2003).

[27] E.O. Hall. Proc. Phys. Soc. B 64, 747 (1951).

[28] D.B. Witkin, E.J. Lavernia. Prog. Mater. Sci. 51, 1 (2006).

[29] N. Hansen, X. Huang. Acta Mater. 46, 1827 (1998).

[30] F.R.N. Nabarro, Z.S. Basinski, D.B. Holt. Adv. Phys. 13, 193 (1964).

[31] O.R. Myhr, O. Grong, S.J. Andersen. Acta Mater. 49, 65 (2001).

[32] K.E. Knipling, D.C. Dunand, D.N. Seidman. Acta Mater. 56, 114 (2008).

[33] W. Lefebvre, N. Masquelier, J. Houard, R. Patte, H. Zapolsky. Scripta Mater. 70, 43 (2014).

[34] C.B. Fuller, D.N. Seidman, D.C. Dunand. Acta Mater. 51, 4803 (2003).

[35] M.A. Meyers, K.K. Chawla. Mechanical metallurgy: principles and applications. Paramus, NJ, Englewood Cliffs (1984).

[36] T.S. Orlova, A.M. Mavlyutov, T.A. Latynina, E.V. Ubyivovk, M.Y. Murashkin, R. Schneider, D. Gerthsen, R.Z. Valiev. Rev. Adv. Mater. Sci. 55, 92 (2018).

[37] A. Hasnaoui, H. Van Swygenhoven, P.M. Derlet. Acta Mater. 50, 3927 (2002).

[38] А.М. Мавлютов, Т.А. Латынина, М.Ю. Мурашкин, Р.З. Валиев, Т.С. Орлова. ФТТ 59, 10, 1949 (2017).

[39] T.S. Orlova, N.V. Skiba, A.M. Mavlyutov, R.Z. Vaiev, M.Y. Murashkin, M.Y. Gutkin. Rev. Adv. Mater. Sci. 57, 224 (2018).

[40] X. Huang, N. Hansen, N. Tsuji. Science 312, 249 (2006).

[41] J. Hu, Y.N. Shi, X. Sauvage, G. Sha, K. Lu. Science 355, 1292 (2017).

[42] Y. Zhang, Sh.J.P. Trimby, M.Y. Murashkin, R.Z. Valiev, G. Sha. Mater. Sci. Eng. A 752, 223 (2019).

[43] A.E. Medvedev, M.Y. Murashkin, N.A. Enikeev, I. Bikmukhametov, R.Z. Valiev, P.D. Hodgson, R. Lapovok. J. Alloys Comp. 796, 321 (2019).

Редактор Т.Н. Василевская 